\title{
Prolepsis and the Environmental Rhetoric of Congressional Politics: Defeating the Climate Stewardship Act of 2003
}

\author{
Richard Besel
}

As a device of argumentative anticipation, prolepsis use generally is considered a positive rhetorical strategy. Turning to the Climate Stewardship Act (CSA) of 2003, this article contributes to our understanding of environmental communication, political argumentation, and rhetorical theory by examining how proleptic miscalculation can actually produce devastating consequences against one's cause when used as a source of invention. Proponents of the CSA relied on creating proleptic arguments grounded in a scientific understanding of climate change to such an extent that they mistakenly downplayed the economic arguments against the Act. This orchestrated miscalculation was encouraged and strengthened by key US senators. This article concludes by discussing contributions to scholarly understanding of prolepsis use in public policymaking and offers practical suggestions for improving communication in future considerations of environmental legislation.

Keywords: Prolepsis; Climate Change; Environmental Rhetoric; US Congress; Climate Stewardship Act of 2003

In June of 2001, the US, under the leadership of President George W. Bush, isolated itself from the international community by refusing to ratify the Kyoto Protocol, a document it helped create (Bush, 2001). Reflecting a reversal of President Bush's campaign promises to cap US carbon dioxide emissions, the decision to permanently withdraw the US from future Kyoto negotiations disappointed many environmentalists (Henneberger, 2001). In the months preceding President Bush's speech, cabinet 
and press officials hinted at the administration's position. In late March, press secretary Ari Fleischer noted that President Bush "does not support the Kyoto treaty" and Environmental Protection Agency Administrator Christie Todd Whitman added the US had "no interest" in supporting the Protocol (Jehl, 2001, p. 22). Despite the predictability of President Bush's decision, activists could not help but feel even more pessimistic about the future when scientists released two new reports.

In May, the Bush Administration sent a letter to the National Research Council (NRC) requesting the group conduct a review of the Intergovernmental Panel on Climate Change (IPCC) (2001) reports to help the Administration identify "the greatest certainties and uncertainties" in climate-change science (NRC, 2001, Appendix A). The NRC's response stated: “Greenhouse gases are accumulating in Earth's atmosphere as a result of human activities, causing surface air temperatures and subsurface ocean temperatures to rise. Temperatures are, in fact, rising" (NRC, 2001, p. 1). In September, the IPCC released another report stating that "there is new and stronger evidence that most of the warming observed over the last 50 years is attributable to human activities" (2001, p. 5). In late 1990s and early 2000s, scientists told policymakers they needed to do something about climate change, but US policymakers were not prepared to have that "something" be the Kyoto Protocol.

Although multilateral action to address climate change seemed unlikely, in 2003, two US Senators who were then from different sides of the aisle, John McCain (R-AZ) and Joseph Lieberman (D-CT), came together to propose a US policy aimed at reducing global warming gas (GWG) emissions (Lieberman is currently holding office as an Independent). They created the Climate Stewardship Act (CSA), popularly known as the McCain-Lieberman bill. The Act (S.139) once again brought global climate change to the forefront of congressional environmental politics.

With the introduction of the CSA in January of 2003, those in favor of slowing global climate change had a number of reasons to view environmental policymaking in the US with a sense of optimism. Not only was the CSA being proposed by two prominent politicians who potentially had the reputations to get the policy enacted, but the CSA had bi-partisan and public support as well. According to a 2003 Gallup poll, 75\% of Americans favored "imposing mandatory controls on carbon dioxide emissions and other greenhouse gases" (Symons, 2003). Public opinion in 2003 was also favorable toward the bill itself. In an October 2003 Zogby poll, 78\% of Americans believed the US should do something to reduce its release of GWGs, with $75 \%$ supporting the CSA in particular (Zogby International, 2003). Dozens of editorials appeared in periodicals throughout the country arguing in favor of passing the CSA (Excerpts of editorials on global warming 2005; Symons, 2003). The bill also gained the support of 155 mayors, the National Farmers Union, the League of Conservation Voters, the League of Women Voters, 175 sportsmen groups, and a variety of religious organizations (Senators McCain and Lieberman reintroduce the climate stewardship act, 2005; The Climate Stewardship Act, 2004). Perhaps most surprising was the support given by various corporate interests, including insurance giant Swiss Re, the American Gas Association, Dupont, General Electric, Maytag, and Trane (Symons, 2003; The Climate Stewardship Act, 2004). However, despite widespread support, 
opponents ultimately defeated the Act on the Senate floor in October of 2003 by a slim margin of 55 to 43 .

Following the vote, a number of puzzling questions remained unanswered: If there was so much public support for legislation aimed at reducing GWG emissions, as well as bi-partisan sponsorship of the bill by two prominent Senators, why did the CSA fail? How did CSA opponents defeat the bill? Could CSA supporters, including McCain and Lieberman, have done more to ensure the passage of the CSA? In addressing these questions, I contend that the CSA defeat in October 2003 was significantly influenced by the rhetorical and argumentative miscalculation of bill supporters, including prolepsis use that was intimately connected to Senate norms of witness selection. This is not to say material interests and power dynamics do not matter. On the contrary, this article focuses on the discursive construction of power by examining how prolepsis was used by CSA proponents. While prolepsis, a strategy of argumentative anticipation, is generally considered a positive rhetorical strategy, this article contributes to our understanding of rhetorical theory by examining how proleptic miscalculation can actually produce devastating consequences against one's cause when that miscalculation becomes a topos of legislative argument. Proponents of the CSA relied on creating proleptic arguments grounded in a scientific understanding of the issue to such an extent that they mistakenly downplayed the economic arguments against the Act. However, this misstep was encouraged. McCain, in his selection of witnesses and steering of the discourse through his use of question and answer sessions, pushed for anticipation of scientific arguments across the testimonies. Proponents of the CSA had the inventional resources available to them to counter their opponents' arguments, but simply failed to use them in their rhetorical orchestration.

The CSA also deserves our attention for environmental policy reasons. As the first serious climate-change policy with potentially far-reaching economic consequences to be engaged by the US since the Kyoto Protocol, the rhetorical dimensions of the CSA's failure in 2003 offer lessons about the procedural constraints associated with Congressional policymaking that can influence the reception and potential success of future environmental legislation. According to public policy scholars Frank Fischer and John Forrester, "As massive environmental problems loom before us, political talk will become more and not less important" (1993, p. 13). The New York Times has called the CSA the "best-known brand in climate-change legislation" Congress has had to consider (Barringer \& Revkin, 2007, p. A24). The notion that proleptic miscalculation could actually harm the interest of the rhetors doing the constructing is an important one, given that virtually all hearings involve some form of argumentative anticipation and are grounded within institutional norms.

The remainder of this article is divided into four sections. First, I begin by discussing the development of the CSA as it progressed from its first committee introduction to the vote on the Senate floor in October 2003. After considering the CSA legislative history, I briefly discuss prolepsis as a rhetorical figure. Next, I analyze the arguments and strategies used by CSA proponents and their opponents during the hearings and floor debate. Finally, I turn to statements made by senators 
following the vote to further illustrate the rhetorical complexity involved in environmental policymaking about global climate change. The proponents may be succeeding in terms of science, but they are failing in terms of rhetorical and political action.

\section{The CSA of 2003}

When the CSA was first introduced to the Senate in January of 2003, it contained two phases for implementation. Phase I consisted of legislation aimed at reducing GWG emissions to their 2000 levels by 2010. Phase II of the bill, the most drastic, included a system of tradable allowances that required emission rollbacks to 1990 greenhouse gas levels once phase I was completed, a task that was closer to the objective of the Kyoto Protocol. In essence, the CSA of 2003 attempted to use the profit motive of corporations to drive an environmentally friendly bill.

Within weeks of the bill's unveiling, numerous economic reports evaluated the Act. Responding to senators' requests, the Department of Energy's (DOE) Energy Information Administration (EIA) released an assessment report in June. The results were mixed: With adoption of the Act US emissions would return to 2000 levels by 2025 and the US would see a decreased dependence on foreign oil. However, the DOE also projected that the Act would cause significant price increases for nearly every fossil fuel and fossil fuel product when compared to a projection without the CSA in place ( $27 \%$ for gas, $46 \%$ for electricity, $31 \%$ for petroleum products, $485 \%$ for coal) and that the US gross domestic product (GDP) would be reduced $\$ 109$ billion (EIA, 2003, p. xii-Xviii). CSA authors quickly amended the Act by eliminating Phase II of the bill - the section that required emission rollbacks to 1990 levels and was the primary cause of the price increases estimated in the DOE report. Two weeks later, the Joint Program on the Science and Policy of Global Change at the Massachusetts Institute of Technology (MIT) also released an economic analysis of the CSA. Their conclusions were far more financially tolerable than the DOE report: the cost of the amended Act could be a rather minimal discomfort of $\$ 20$ per year per household (Paltsey, Reilly, Jacoby, Ellerman, \& Tay, 2003, p. 27). It seemed as though the CSA supporters had a bill they could now argue was financially reasonable. However, in October, just before McCain and Lieberman were to introduce the bill onto the floor of the Senate, Charles River Associates, a Boston-based financial and economic consulting firm, concurred with the DOE assessment of double-digit price increases when they examined the bill's effects with Phase II included in the economic models. It also acknowledged the bill's costs were much lower when Phase II was left out (Smith, Bernstein, \& Montgomery, 2003, , p. 3). In terms of economic reports, both sides possessed inventional resources to construct their arguments for and against the CSA.In addition to being subjected to economic scrutiny, the CSA also had to survive congressional hearings before debuting on the Senate floor. In 2003, as chairman of the Committee on Commerce, Science, and Transportation, McCain held three hearings to build his case for the CSA's passage. The initial hearing was held on January 8, 2003, the committee's first meeting of the year. This bill was also the first business item the committee considered. 
The second hearing was held before the subcommittee on Science, Technology, and Space on June 6, 2003. The last was held on October 1, 2003, before the Committee on Commerce, Science, and Transportation.

Over the course of these hearings, McCain invited dozens of witnesses-mostly scientists - to testify about the current state of climate-change science, the CSA, and what other nations were doing to combat climate change. However, testimony was heavily slanted in favor of the CSA, primarily because McCain was the one doing most of the selecting. The obvious one-sided nature of the hearings is not an unusual occurrence; Senate norms and structural rules have allowed committee chairs and staff members to use their influence to determine the general tone of hearings for decades, deciding "who should testify, when, and on what issues" (Oleszek, 1978, p. 68). Indeed, chairs often use their power to "give positions of privilege and potential influence" to witnesses (Gross, 1953, p. 311). Tarla Rai Peterson has noted in her study on institutional authority in Senate subcommittee hearings that "a hearing provides opportunity for groups to frame a situation around their own interests" (1988, p. 261). With an interested committee chair, it is no surprise that the witnesses who are selected to testify often concur with the chair's opinions on the given topic, creating a "sectional or group bias" (Galloway, 1953, p. 299). Some scholars have even noted the way hearings have been used as a test ground for arguments before presenting them on the floor during open debate (Butler, 1995). However, unlike previous studies where policymakers were documented using hearings to successfully adjust their floor arguments, CSA proponents met with failure. The CSA was brought onto the floor of the Senate on October 29, 2003, and defeated on October 30, 2003. In the remainder of this article, I turn to these three hearings and the two-day floor debate to illustrate how CSA supporters' miscalculation paralyzed passage of the new policy and how potentially useful inventional resources, such as economic reports, were rhetorically (mis)handled. The Senate norm of allowing committee chairs to determine the tone of the rhetoric produced during the hearings via witness selection created the conditions to sustain the use of prolepsis as not just a figure, but also as a source of invention. However, before turning to the actual texts, a consideration of how prolepsis is usually defined and used is in order.

\section{Argumentative Anticipation: Prolepsis as a Figure and Source of Invention}

Prolepsis, following Richard Lanham's definition, is the rhetorical tactic of "foreseeing and forestalling objections." According to Lanham, this foreseeing and forestalling involves a "preconception" and "anticipation" of arguments against one's position (Lanham, 1991, p. 120). Rhetoricians and persuasion scholars have discussed prolepsis in a number of ways, but they do not necessarily use the same terms. Although prolepsis is used synonymously with a number of Greek and Latin figures (e.g., prokatalepsis and anticipatio), Michael Leff and Jean Goodwin note that each of these terms simply "designates minute differences in form and function" (2000, p. 59). Although I agree with Leff and Goodwin's assessment, a brief exploration of the origins and nature of these differences is in order. 
In ancient Greece and Rome, prolepsis was often understood by orators to have two different meanings. First, prolepsis could be defined as the use of an anticipatory figure at the sentence level. In his text Greek Grammar, Herbert Smyth notes that the ancient Greeks used prolepsis when "the subject of the dependent clause is often anticipated and made the object of the verb of the principle clause" (1973, p. 488). Smyth (1973) offers a classic example: "Consider the lilies of the field how they grow" (p. 683). However, Smyth also notes a second meaning: "Prolepsis is also used to designate the anticipation of an opponent's arguments and objections" (1973, p. 683). Some scholars have noted how prolepsis in this second definition is "a synonym for procatalepsis, the anticipation and answering of an opponent's argument" (Myers \& Simms, 1985, p. 243). Heinrich Lausberg also calls anticipatio "proleptic defensive anticipation of the opponent's argument" (1998, p. 383). These two definitions of prolepsis initially formulated by the ancient Greeks continued to be used by the Romans. However, it was the second that received the most treatment in many of the classic Roman texts. Some of the most famous Roman rhetoricians were well-versed in the use of prolepsis as an argumentative and inventional device of anticipation. In his Institutes of Eloquence, Quintilian, following Cicero's lead, called prolepsis a kind of "anticipation, by which I mean our answering of objections which we foresee" (Quintilian, 1805, p. 161). However, prolepsis is not a figure that has been left to the pages of rhetorical history books. Prolepsis is also being engaged in contemporary texts (Bridgeman, 2005; van Eemeren \& Houtlosser, 2000).

Social scientists concerned with persuasive effects of communication have contributed substantially to scholarly understanding of the proleptic strategy in their work on "one-sided" versus "two-sided" messages. By one-sided messages, this group of scholars refers to communication that only uses evidence and arguments "favoring the recommended conclusion." Thus, two-sided arguments are those that address evidence and arguments both for and against a position (Petty \& Cacioppo, 1996, p. 74). Refutational two-sided messages contain counterarguments to the communicator's position or desired outcome, but are addressed in a way that favors the communicator. Early studies conducted in the 1950s by Carl I. Hovland, Arthur A. Lumsdaine, and Fred D. Sheffield (1967) indicated "presenting arguments on both sides of an issue was found to be more effective than giving arguments supporting the point being made, in the case of individuals who were initially opposed to the point of view being presented" (p. 94). For those who were already convinced of this point of view, "the inclusion of arguments on both sides was less effective" when compared to the one-sided experimental condition (Hovland, et al., 1967, pp. 94-95). In other words, early studies indicated prolepsis should be used when a rhetor is attempting to convince an audience that is against his or her position.

Following the studies of the 1950s, one-sided versus two-sided messages have received a great deal of attention. In his meta-analysis on the subject, Daniel O'Keefe (1999) gathered over 107 studies for inclusion in his review. O'Keefe indicates that the research conducted on one-sided versus two-sided messages no longer supports the early contention that initial audience position matters. Instead, what matters is whether or not the two-sided message is refutational (does the rhetoric simply 
identify opposing arguments, or does the rhetor identify and refute the arguments) and whether or not the message is commercial advertising. O'Keefe found that refutational two-sided messages are more persuasive than one-sided or nonrefutational two-sided messages in non-commercial messages. In other words, using prolepsis is generally more persuasive than not.

Although prolepsis has been labeled in a variety of ways, it is generally viewed by commentators as good rhetorical strategy. Quintilian (1805) noted that prolepsis could be of "great service in a pleading" (p. 161). Leff and Goodwin (2000) argue Abraham Lincoln's success as a rhetor is, at least partially, attributable to his use of rhetorical figures such as prolepsis. However, as we shall see in the case of the CSA, using prolepsis is not always a positive feature of discourse. Hovland et al. (1967) were right about one all-too-brief observation:

An important incidental finding was that the absence of one relevant argument against the stand taken by the programs was more noticeable in the presentation using arguments on both sides than in the presentation in which only one side was discussed. (p. 95)

As we shall see, the absence of relevant arguments in the CSA proponents' discourse worked against their cause. When combined with the selection norms of the Senate, proleptic miscalculation can be sustained across the testimonials, producing devastating results against a rhetor's desired outcome.

\section{Scientific Argumentation and Proleptic Miscalculation}

From January to October 2003, supporters and opponents of the CSA delivered hundreds of arguments. What many of the supporters had in common was their coupling of scientific arguments and a sense of argumentative anticipation. The decision to focus on scientific arguments was primarily a result of proleptic strategy. This general coupling is not unusual given the previous decade of climate change discourse in the US Congress. Ross Gelbspan has argued effectively that scientific challenges and the creation of scientific uncertainty within the House and Senate were common practices from the late 1980s through the late 1990s (1998, pp. 67-82, 198-237). Thus, the decision of CSA proponents to anticipate scientific challenges should not come as a surprise. However, the rhetoric of CSA proponents suffered from a significant rhetorical miscalculation: proponents engaged and committed to a form of prolepsis that left the CSA devastatingly vulnerable to economic attacks.

From the very first hearing held in January of 2003 before the Senate Commerce, Science, and Transportation Committee, CSA supporters chose to frame their arguments from a scientific vantage point. In the first paragraph of McCain's introductory remarks, he referenced the National Academy of Sciences report, especially where it noted, "gases are accumulating in the Earth's atmosphere as a result of human activities, causing surface air temperatures and subsurface ocean temperatures to rise. Temperatures are, in fact, rising" (FDCH, 2003c, p. 2). By focusing on evidence that tells us climate change is a "fact," McCain revealed his belief that science was clearly on his side and that the science relating to global 
climate change has produced certain knowledge. McCain went on to paraphrase the findings of the National Oceanic and Atmospheric Administration, researchers at the University of Texas, Weslyan University, Stanford University, and the journal Nature, all in an attempt to show climate change was a real phenomenon taking place right now (FDCH, 2003c, p. 2). By piggybacking on the credibility of well-respected scientific authorities, McCain attempted to convince his audience that scientific evidence and accuracy were the criteria it should be using to determine whether or not the CSA should be passed. For McCain, the science was settled and there was no reason the Senate should vote against the bill.

Although it seems clear McCain's introductory comments addressed scientific issues, it is not until the second page of his arguments that one understands how prolepsis plays a role in McCain's decision to feature heavily scientific arguments. Given Gelbspan's observations about the constant and consistent scientific challenges from climate-change skeptics in previous hearings, one would suspect an experienced senator such as McCain would be familiar with the legislative history. However, we should not let the coupling of prolepsis and the scientific arguments rest on an assumption. McCain reveals his coupling of prolepsis and scientific argumentation in the following:

The United States must do something. But it must also do the right thing. Many have focused on what we do not know or the uncertainties around climate change. I prefer a more sound and scientific approach of starting with what is known or given and then proceeding to solve the problem at hand. (FDCH, 2003c, p. 3)

For McCain, the most important thought, the thought he decides to place in the recency position of his speech, is that the "many" who have focused on the "uncertainties" are in the wrong; a "sound and scientific approach" is the one he has adopted. By the end of McCain's remarks the relationship between anticipating scientific arguments and the decision to preemptively shore up the scientific case for the existence of climate change is clear.

Although McCain's decision to feature scientific arguments appears to be linked to an anticipation of skeptics' arguments, McCain also uses his position during the question and answer sessions to highlight this linkage. For example, when James Mahoney, Assistant Secretary of Commerce for Oceans and Atmosphere and Director of the US Climate Change Science Program, attempted to widen the discussion beyond scientific considerations, McCain's first question was about the scientific status of global climate change $(\mathrm{FDCH}, 2003 \mathrm{c}, \mathrm{p} .13)$. Time and again, McCain appeared certain the CSA would be challenged primarily on scientific grounds.

Following McCain's lead and adopting a similar anticipatory mindset, other Senators and witnesses also used the scientific frame to situate their arguments. Scientific arguments saturate the texts of the hearings primarily because CSA proponents also engaged in a collective, rhetorical construction of their opponents' arguments. CSA supporters assumed the opponents would continue to attack the legitimacy of climate-change science or suggest scientists and Congress did not know enough about it to make informed policy decisions. For example, Senator Ron 
Wyden (D-OR) summarily proclaimed in his opening statement, "The fact of the matter is, there is clear evidence, with respect to what is causing the problem" (FDCH, 2003c, p. 3). Similar to McCain's remarks, Wyden decides to feature the science first. Also like McCain, Wyden's reason for featuring scientific argumentsanticipation of skeptical counterarguments - appears later in his commentary: "If you really think about it, what they are constantly saying is that we just can't get any further than research. We deny, in effect, all of what you all have said, that you can have these positive programs" (FDCH, 2003c, p. 31). Wyden's "they" are unnamed individuals, but he is certain about the kind of argument that has been the most problematic for climate-change believers. Throughout the first hearing, CSA supporters and witnesses echoed similar assessments. Climate-change believers have been challenged in the past and will likely be challenged again. However, "clear evidence" exists about causes; global climate change is a matter of "fact;" the science is "unchallengeable." Arguments rooted in science began to take on the flavor of arguments rooted in a rhetoric of certainty.

In the March and October hearings, the same proleptic/scientific argument coupling was used yet again. Dr. Antonio Busalacchi of the NRC spent the overwhelming majority of his testimonial time focusing on "what most scientists believe to be true." Busalacchi summarized: "Despite the uncertainties, however, there is widespread agreement that the observed warming is real, and particularly strong within the past 20 years." Busalacchi's statement was supported by "a diverse array of evidence" and "instrumental records," leaving him with "no doubt that humans have modified the abundance of key greenhouse gases in the atmosphere" (FDCH, 2003a, p. 6). In a telling exchange with Senator Bill Nelson (D-FL), and similar to McCain and Wyden's speeches, Busalacchi's anticipation of skeptical counterarguments can also be observed:

MR. BUSALACCHI: I made the remark that the press portrays our problem ashaving a community over here in favor of global warming and a community over here -

SEN. NELSON: And that's not the way it is.

MR. BUSALACCHI: No, it's like this.

SEN. NELSON: It's 95 to 5.

MR. BUSALACCHI: The preponderance of evidence is way over here that globalwarming is real, and it's time now to take action.

SEN. NELSON: Do the 5 percent really believe it, or are they paid to say that?

MR. BUSALACCHI: Yes. (Laughter.) (FDCH, 2003b, p. 15)

Embedded within this comical exchange is the construction of an unidentified group of skeptics who are paid by fossil fuel special interests and believe global warming is not happening. However, the laughter and quantification indicate proponents of the bill are in the right. The "preponderance of evidence" and 95\% of the world's scientists are on their side.

Expanding on Busalacchi's testimony, Dr. Tom Wigley of the National Center for Atmospheric Research focused on the twentieth century warming by examining satellite data. Concurrent with Busalacchi, Wigley concluded: "We can't explain the 
twentieth century warming unless we included human influences" (FDCH, 2003a, p. 8). Also similar to those who spoke before him, Dr. Wigley constructed the CSA opponents and their anticipated arguments: "But there are many people who are opposed to us taking any action who will claim that this is just one of those actions of history, exactly as the ice age was a [sic] well" (FDCH, 2003b, p. 10). Like so many other CSA supporters at the hearings, Wigley, in anticipating the well-known skeptic argument that humans cannot possibly disrupt or significantly influence the natural cycle of ice ages, informs his decision to emphasize science through his use of prolepsis.

From the beginning to the end of the hearing process, CSA proponents were featuring arguments situated in scientific rhetoric because of their common anticipation of what was to come. Global climate change was happening, humans were the cause, the consequences were negative, we must act now, and someone is going to challenge everything we know as scientifically true. For CSA supporters, the scientific evidence needed to be featured in the hearings not only to convince those who were unaware of the scientific state of global climate change research but also to create the conditions that would make it easier for bill supporters to fend off arguments from "others" who wished to challenge the legitimacy or certainty of the science. Thus, the focus of CSA supporters was not so much on the trivial uncertainties, but on the "sound and scientific approach" that ultimately should have allowed the Senate to take action by voting in favor of the CSA.

\section{Arguments Rooted in Economics and Misunderstanding}

By the time the CSA reached the floor of the Senate in late October, bill supporters positioned their arguments during the hearings in a way to give the appearance science was on their side. However, the primary arguments against the CSA had already surfaced in the hearings. Senator Conrad Burns (R-MT) expressed his concerns in January: "I'm not going to participate in any kind of program that exports more jobs from this country. And we've already got a flood of jobs leaving our country. And I'm just not going to contribute to that" (FDCH, 2003c, p. 5). CSA supporters did not engage Burns' statement in the hearings process directly, but they were soon to find out others were in agreement with his position. What was to ensue on the floor of the Senate was nothing short of a discursive reversal from what had taken place during the hearings: scientific arguments were about to take a backseat to economic ones. In other words, the use of prolepsis was about to backfire on CSA supporters.

Senator Lieberman began the first day of the floor debate by relying on the science strategy CSA supporters had used throughout the hearings. However, Lieberman's opening statement was only one of the few times the economic arguments in favor of the CSA were mentioned. Following his prepared remarks, Senator McCain posed a question to Senator Lieberman to bring the focus back to the scientific frame: 
SEN. MCCAIN: Is the Senator aware the major attack on this legislation will be related to the validity of the entire issue of climate change?

SEN. LIEBERMAN: I expect that will be true. (Congressional Record, 2003, p. 8)

McCain then asked a follow-up "question" that was more of a speech. He noted the findings of the 2001 IPCC and the Bush Administration's request for the 2001 NAS report that both pointed to "human activities" as the chief cause for climate change (Congressional Record, 2003, p. 8). After nearly 30 lines of text dedicated to the science behind climate change, McCain did not really end with a question at all: "I ask my colleague to comment on that" (Congressional Record, 2003, p. 9). Lieberman replied: "I expect, unfortunately, that we will debate the science here" (Congressional Record, 2003 , p. 9). The term "unfortunately" is key to understanding Lieberman's, and, I would argue, the CSA proponents' position because it illustrates the high level of certainty CSA supporters had in regards to climate-change science and the kinds of argument they would encounter. It would be unfortunate for them to have to debate the validity of something they already assumed was true. As it turns out, the arguments McCain, Lieberman, and CSA supporters expected to hear were not the primary threat. Opponents were finally going to have their chance to engage the CSA supporters in open debate.

Led by Senator James Inhofe (R-OK), opponents to the CSA shifted the evaluative mode from one concerning questions of science to one primarily concerned with economics. Although Senator Inhofe, in his first floor statement following Senator Lieberman, briefly and boldly challenged the scientific arguments that had been constructed by CSA supporters by noting "some of the things they are saying are untrue," Inhofe did far more to set up the upcoming economic arguments by yielding the floor to Senator Kit Bond (R-MO) (Congressional Record, 2003, p. 9). Bond set the stage for the rest of the debate with the following: "I strongly believe this bill will cripple our economy, cripple our communities, and financially cripple many of our struggling families" (Congressional Record, 2003, p. 10). For CSA opponents, this was not going to be a debate about science or a little economic discomfort; this was a debate about "crippling" an otherwise healthy economy. The CSA was not just a bad idea, it was disabling.

The trope of economic health and disability can be seen throughout the debate and constitutes the majority of CSA opponents' arguments. Focusing on the numbers that illustrated the disabling potential of the CSA proved to be a key way of arguing against the CSA. Senator Bond then referenced the EIA report: "Experts conclude that the legislation under consideration to cut carbon dioxide in electric powerplants [sic] would cost the economy over $\$ 100$ billion. That is one-zero-zero billion dollars. Experts also estimate that the electricity bills would go up by about 40 percent" (Congressional Record, 2003, p. 10). Later in his speech Bond also argued the CSA will "cost millions of American jobs" and that it would "cause a cumulative decrease in the gross domestic product of $\$ 1.4$ trillion" (Congressional Record, 2003, p. 11). After hammering the CSA with economic statistics, Bond once again returned to the trope of ill health: "The effect of this bill would be, first, to send our economy back into recession, then strip the nation of hundreds of thousands of jobs, and then increase 
the cost of heating our homes. I, frankly, cannot think of a better combination of ills" (Congressional Record, 2003, p. 11). The expected arguments about science were only a secondary theme in the first speeches of the October floor debate. Instead, economic health arguments about "ills" were the primary source of resistance against voting for the CSA, even though, as we shall see, those very arguments were based on a faulty understanding of the bill.

When given the chance to respond to the first volley of attacks, supporters of the CSA had difficulty answering all of the arguments. McCain rightly attempted to clarify the confusion extending from Senator's Bond's use of the EIA. Recall that the EIA report only estimated the CSA's effects if both Phases I and II were in effect. McCain briefly noted, "That was a well-written presentation by my colleague from Missouri. Unfortunately, his analysis of the bill is not the bill that is before the Senate. But other than that, it was pretty convincing" (Congressional Record, 2003, p. 11). McCain attempts to shift the economic debate to favor the CSA by noting how Bond did not address the newest version of the bill. However, the economic arguments from opponents continued to reference the EIA evaluations of the old version of the CSA.

Climate Stewardship Act opponents refused to examine the analyses that suggested the CSA would only have minimal economic consequences with Phase II eliminated from the legislation. Senator George Voinovich $(\mathrm{R}-\mathrm{OH})$ continued to reference the EIA report despite McCain's brief attempt to clarify the matter (Congressional Record, 2003, p. 21). Toward the end of the first day of debate, Senator Inhofe turned the misuse of EIA reports against CSA supporters by suggesting opponents who were preparing arguments against the CSA's passage had been, in some way, sandbagged:

It is a little unfair and unrealistic - and I want to make sure everyone interested in this issue understands, we have had the McCain-Lieberman bill for months now, and we have all had a chance to study it. The fact they changed this bill and they are saying you are not talking about the bill before you now, that did not happen until 11:53 this morning. We have not had a chance to see it. (Congressional Record, 2003, p. 27)

Although daily changes to any bill, as long as they follow proper amending procedures, are allowed in the Senate, Inhofe's accusations of unfairness might carry weight if opponents were truly unable to prepare for the debate. However, the changes to the bill were publicly announced by McCain during the October 1 hearing, well before the debate on October 29 and 30 (FDCH, 2003b, 2). The economic analyses from MIT, which included scenarios that eliminated Phase II, were also widely available well before the debate. Nonetheless, CSA supporters did little to engage opponents who reiterated the economic arguments against the original version of the CSA when it was the newer version that was being considered on the floor.

In addition to Senator McCain's brief attempt to clarify the economic confusion about the most recent version of the bill, Senators Lieberman and Diane Feinstein (D-CA) also made attempts to draw attention to the numbers that favored the CSA (Congressional Record, 2003, p. 55). However, McCain's brief correction, Lieberman's 
attempts to introduce the MIT report into the record, and Feinstein's attempt to reveal bias constituted only a small portion of the overall debate and could do little to stop the flawed numbers from entering the discussion. On the second day of the debate, Senator Voinovich appeared to have an answer to the "your economic claims are irrelevant" argument:

I would also like to address statements by Senator McCain and Senator Lieberman that because they offered a substitute to their original version of S. 139, all the comments and analyses cited by opponents of this bill, including myself, are irrelevant. That statement could not be further from the truth. I refer to a letter I recently received from many of the stakeholders against S. 139. (Congressional Record, 2003, p. 67)

After reading an excerpt from the letter testifying to the harsh economic conditions that would result with adoption of S. 139, Senator Voinovich asked the letter, in its entirety, be printed into the record. Voinovich attempted to make it appear as though there were independent economic reasons not based on the EIA report to vote against the CSA. However, after examining the letter, it is clear that the document's conclusions were based on the "Energy Information Administration" (Congressional Record, 2003, p. 67). Because audience members did not really have an opportunity to see the letter or hear it read in its entirety during the debate, Voinovich gave the impression his arguments came from concerned citizens testifying about their potential economic losses rather than the EIA report.

Despite realizing what was happening in terms of the economic arguments, CSA proponents already made the decision to continue emphasizing their argumentative strengths: the science. Halfway into the debate, Senator Lieberman actually started to view the refusal of CSA opponents to primarily engage in a science-oriented argument as progress: "I suppose in some sense we are progressing in this disagreement. I would rather disagree about the impact of the bill than disagree about the science that I think says so clearly the world has a problem. The globe is warming. It is the result of human activity" (Congressional Record, 2003, p. 28). Notice that Lieberman shifts from discussing the economic impact of the bill to emphasizing the science. Considering that Lieberman was one of the primary voices on the floor of the Senate who discussed the economic benefits of the bill and argued against the misunderstood arguments of the CSA opponents, this shift is quite significant. CSA supporters were left without a substantial number of voices on the first day of debates to take on the economic issues.

\section{The Rhetorical Complexity of Proleptic Miscalculation}

Although Senate debates ultimately come to a decision of voting "aye" or "nay," individual reactions are often far more diverse than a vote indicates. Even in my analysis of the CSA hearings and debates, I have paid careful attention to the two dominant rhetorical postures that emerged from the texts. However, following the CSA's defeat in October 2003, a number of senators revealed their reasons for voting 
against the bill. It is in these final texts that one finds a host of complex reasoning processes at work despite the initial appearance of only a two-sided debate.

In the CSA debate, senators cannot simply be divided into two categories of for and against. Not only did some senators completely agree with McCain or Inhofe, but, some also found both arguments equally persuasive. If McCain said the science was right and Inhofe said the economics were wrong, some senators concluded both were correct. When put in that situation, many decided to play it safe and vote against the bill - despite their belief that global climate change was real-because they believed something better could be developed. For example, Senator Arlen Specter (R-PA) acknowledged "global warming is a matter of great international importance," but voted against the bill because "national and state economies" are "very fragile at the moment” (Congressional Record, 2003, p. 99). Senator Lincoln (D-AR) echoed a similar reasoning process:

Mr. President, although I am extremely concerned about global warming, I voted against Mr. McCain and Lieberman's Climate Stewardship Act. My chief concern was that this bill would raise gas and electric prices at a time when Arkansas's economy is struggling to recover and many residents from my state are finding it difficult to make ends meet. (Congressional Record, 2003, p. 100)

Senator Max Baucus (R-MT) shared his opinion that "global climate change is a serious problem," while also believing the CSA would have "impacts on my state, particularly agriculture, from increased gas prices" (Congressional Record, 2003, p. 101). These comments were generated despite studies indicating the CSA would only have a minimal economic impact (e.g., Paltsey et al., 2003, p. 2003). And there is an element of timing that becomes vital to understanding resistance to the CSA. The potential for a drain on the economy was too much for many policymakers, especially middle-of-the-road senators, to risk in light of a potentially unending war on terror, recovering state economies that had gone through recent recessions, and rising gas prices. Put simply, CSA proponents did not do enough to preempt and address the economic arguments or the timing of the bill. Given the political and economic context, it is remarkable CSA proponents did not sufficiently anticipate economic arguments from their colleagues, further emphasizing the importance of anticipating the most powerful arguments against one's position. Opponents successfully stifled passage of the CSA, not because their arguments were undeniable, but because they presented an evaluative rhetorical posture that resonated with senators and could coexist with the scientific arguments proposed by CSA supporters.

Although the rhetorical construction of others and their arguments has been discussed in the canon of rhetorical theory, with most studies indicating the use of prolepsis helps the rhetor's cause, few studies have examined the way proleptic miscalculation has the potential to harm the interest of the rhetors doing the anticipating when it shifts from mere figural use to a systemically encouraged topos. With the CSA, the decision to anticipate opponents' arguments against the bill as focusing on scientific grounds actually did more to harm the CSA supporters' cause than a decision to imagine an array of arguments. In fact, one could even claim using 
prolepsis for the scientific arguments was successful in shifting the opponents toward economic claims. Thus, CSA supporters, perhaps, did not use prolepsis to its fullest extent because they did not anticipate the economic arguments. This analysis falls in line with Hovland et al.'s (1967) brief observation that using prolepsis while omitting a significant component of counterarguments could produce undesired effects. When confronted with the actual opponents and their arguments, as opposed to the ones from the hearings, CSA supporters were not as prepared as they could have been for the omitted economic arguments. Inventional resources that could have stifled some of the opponents' arguments went unused. The MIT study was only briefly referenced and only a handful of Senators actually engaged economic arguments. This is similar to Robert Cox's observation that recent climate communication campaigns have become "non-adaptive" (2010, p. 122). However, the contribution this article makes to our understanding of rhetorical theory lies primarily in the connection between proleptic miscalculation and the orchestrated efforts within an institutionalized deliberative setting. Senate norms allowed individuals in positions of power to select witnesses and questions that directed the flow of discourse in the same direction. This analysis highlights the way prolepsis was adopted across texts in a singular and narrowly defined effort to pass legislation. Prolepsis should no longer be viewed as a simple stylistic figure that resides in singular texts, nor should prolepsis be seen as an "old" or "classical" concept that is of no consequence for today's rhetorical critics. Instead, it should now also be viewed as a powerful and inventional driver of environmental discourse alongside other genre-like or trope-oriented argument forms in our attempts to "recover the strategic" in climate-change communication (Cox, 2010, p. 122).

Finally, there is also a critical and practical environmental communication suggestion to be made from this analysis. McCain and Lieberman repeated their attempts to rhetorically construct a scientific frame of analysis for a new version of the CSA in the three hearings held from late 2004 to early 2005. Once again, the CSA was defeated. To avoid repeating mistakes they made in 2003 through 2005, McCain and CSA supporters need to adjust their rhetoric to address better the economic arguments so passionately advanced by senators like Inhofe. Legislators who wish to introduce similar policies should also learn from this example. This case underscores the importance of engaging not just the scientific elements of climate change rhetoric, but also the non-scientific concerns such as economics. The arguments are available to those who believe climate change needs to be addressed; they simply must choose to invoke them if we are ever to have significant policy changes to address this pressing environmental problem.

\section{References}

Barringer, F., \& Revkin, A.C. (2007, January 18). Measures on global warming move to spotlight in the new congress. New York Times, p. A24.

Bridgeman, T. (2005). Thinking ahead: A cognitive approach to prolepsis. Narrative, 13, 125-159. 
Bush, G.W. (2001, June). President discusses global climate change. Retrieved from http://www. whitehouse.gov/news/releases/2001/06/print/20010611-2.html

Butler, J. (1995). Carol Moseley-Braun's day to talk about race: A study of forum in the United States Senate. Argumentation \& Advocacy, 32, 62-74.

Congressional Record. (2003). 108th Congress. 1st session. October 29 \& 30.

Cox, R. (2010). Beyond frames: Recovering the strategic in climate communication. Environmental Communication: A Journal of Nature and Culture, 4, 122-133.

Energy Information Administration (EIA). (2003). Analysis of S.139, the climate stewardship act of 2003. Washington, DC: Department of Energy.

Excerpts of editorials on global warming. (2005, March 1). Retrieved from http://www.edf.org/ article.cfm?contentID $=3344$

Federal Document Clearing House (FDCH). (2003a, March 3). Climate change. Retrieved from Academic Universe, Lexis-Nexis database.

Federal Document Clearing House (FDCH). (2003b, October 1). Panels I and II of a hearing of the senate commerce, science, and transportation committee. Retrieved from the Academic Universe, Lexis-Nexis database.

Federal Document Clearing House (FDCH). (2003c, January 8). Senator John McCain holds a hearing on the proposal to create a mandatory greenhouse gas emission reduction. Retrieved from the Academic Universe, Lexis-Nexis database.

Fischer, F., \& Forrester, J. (1993). Editors' introduction. In F. Fischer \& J. Forrester (Eds.), The argumentative turn in policy analysis and planning (pp. 1-17). Durham: Duke University Press.

Galloway, G.B. (1953). The legislative process in Congress. New York, NY: Thomas Y. Crowell Company.

Gelbspan, R. (1998). The heat is on: The climate crisis, the cover-up, the prescription. Reading, MA: Perseus.

Gross, B.M. (1953). The legislative struggle: A study in social combat. New York, NY: McGraw-Hill.

Henneberger, M. (2001, April 17). Despite appearances, Whitman says she and Bush agree on environment. New York Times, p. A12.

Hovland, C.I., Lumsdaine, A.A., \& Sheffield, F.D. (1967). The effects of presenting "one side" versus "both sides" in changing opinions on a controversial subject. In R.L. Rosnow \& E.J. Robinson (Eds.), Experiments in persuasion (pp. 71-95). New York, NY: Academic Press.

Intergovernmental Panel on Climate Change (IPCC). (2001). Climate change 2001: Synthesis report: Summary for policymakers. Retrieved from http://www.ipcc.ch/pub/un/syreng/spm.pdf

Jehl, D. (2001, March 29). U.S. going empty-handed to meeting on global warming. New York Times, p. 22.

Lanham, R. (1991). A handlist of rhetorical terms. Berkeley, CA: University of California Press.

Lausberg, H. (1998). Handbook of literary rhetoric: A foundation for literary study (D.E. Orton \& R.D. Anderson, Jr., Eds., M.T. Bliss, A. Jansen, \& D.E. Orton, Trans.). Boston: Brill.

Leff, M., \& Goodwin, J. (2000). Dialogic figures and dialectical argument in Lincoln's rhetoric. Rhetoric \& Public Affairs, 3, 59-69.

Myers, J., \& Simms, M. (1985). Longman dictionary and handbook of poetry. New York, NY: Longman.

National Research Council (NRC). (2001). Climate change science: An analysis of some key questions. Washington, DC: National Academy Press.

O'Keefe, D.J. (1999). How to handle opposing arguments in persuasive messages: A meta-analytic review of the effects of one-sided and two-sided messages. In M.E. Roloff (Ed.), Communication Yearbook: 22 (pp. 209-249). Thousand Oaks, CA: Sage.

Oleszek, W.J. (1978). Congressional procedures and the policy process. Washington, DC: Congressional Quarterly Press. 
Paltsey, S., Reilly, J.M., Jacoby, H.D., Ellerman, A.D., \& Tay, K.H. (2003). Emissions trading to reduce greenhouse gas emissions in the United States: The McCain-Lieberman proposal. Cambridge, MA: Joint Program on the Science and Policy of Global Change.

Peterson, T.R. (1988). The rhetorical construction of institutional authority in a Senate subcommittee hearing on wilderness legislation. Western Journal of Speech Communication, 52, 259-276.

Petty, R.E., \& Cacioppo, J.T. (1996). Attitudes and persuasion: Classic and contemporary approaches. Boulder, CO: Westview Press.

Quintilian. (1805). Quintilian's institutes of eloquence: Or, the art of speaking in public, in every character and capacity (W. Guthrie, Trans.). London: Dewick and Clark.

Senators McCain and Lieberman reintroduce the climate stewardship act. (2005, February 10). Retrieved from http://www.edf.org/article.cfm? contentID $=4314$

Smith, A.E., Bernstein, P., \& Montgomery, W.D. (2003). The full costs of S. 139, with and without its phase II requirements. Washington, DC: Charles River Associates.

Smyth, H.W. (1973). Greek grammar. Cambridge: Harvard University Press.

Symons, J. (2003, October 3). Support for the climate stewardship Act (S.139). Retrieved from http://www.ciel.org/Publications/Climate_Testimony_21Oct03.pdf

The climate stewardship act. (2004). Retrieved from http://www.arizonaenergy.org/Legislation/ climate_stewardship_act.htm

van Eemeren, F.H., \& Houtlosser, P. (2000). Rhetorical analysis within a pragma-dialectical framework: The case of R.J. Reynolds. Argumentation, 14, 293-305.

Zogby International. (2003, October 21). Results from October Zogby America poll. Utica, NY: Zogby International. 